\title{
A new euselachian shark from the early Permian of the Middle Urals, Russia
}

\author{
Alexander O. Ivanov, Christopher J. Duffin, and Serge V. Naugolnykh \\ Acta Palaeontologica Polonica 62 (2), 2017: 289-298 doi:https://doi.org/10.4202/app.00347.2017
}

The isolated teeth of a new euselachian shark Artiodus prominens Ivanov and Duffin gen. et sp. nov. have been found in the Artinskian Stage (Early Permian) of Krasnoufimskie Klyuchiki quarry (Sverdlovsk Region, Middle Urals, Russia). The teeth of Artiodus possess a multicuspid orthodont crown with from four to nine triangular cusps; prominent labial projection terminating in a large round tubercle; distinct ornamentation from straight or recurved cristae; oval or semilunar, elongate, considerably vascularized base; dense vascular network formed of transverse horizontal, ascending, short secondary and semicircular canals. The teeth of the new taxon otherwise most closely resemble the teeth of some protacrodontid and sphenacanthid euselachians possessing a protacrodont-type crown, but differ from the teeth of all other known euselachians in the unique structure of the labial projection. The studied teeth vary in crown and base morphology, and three tooth morphotypes can be distinguished in the collection reflecting a moderate degree of linear gradient monognathic heterodonty. The range of morphologies otherwise displayed by the collection of teeth shows the greatest similarity to that described for the dentitions of relatively high-crowned hybodontids from the Mesozoic. The internal structure of the teeth, including their vascularization system is reconstructed using microtomography. The highest chondrichthyan taxonomic diversity is found in the Artinskian, especially from the localities of the Middle and South Urals.

Key words: Chondrichthyes, Elasmobranchii, teeth, Permian, Russia, Urals.

Alexander O. Ivanov [IvanovA-Paleo@yandex.ru], Institute of Earth Sciences, St. Petersburg State University, 16 Liniya 29, St. Petersburg, 199178, Russia; Kazan Federal University, 18 Kremlevskaya ul., Kazan, 420008, Russia. Christopher J. Duffin [cduffin@blueyonder.co.uk], Palaeontology Section, Earth Science Department, The Natural History Museum, Cromwell Road, London, SW7 5BD, UK; current address: 146, Church Hill Road, Sutton, Surrey SM3 8NF, UK. Serge V. Naugolnykh [naugolnkh@list.ru], Geological Institute of Russian Academy of Sciences, 7, Pyzhevsky per., Moscow, 119017, Russia; Kazan Federal University, 18, Kremlevskaya ul., Kazan, 420008, Russia. 
This is an open-access article distributed under the terms of the Creative Commons Attribution License (for details please see creativecommons.org), which permits unrestricted use, distribution, and reproduction in any medium, provided the original author and source are credited.

Fafill text $(888.2 \mathrm{kB})$ 